Research Paper

\title{
Identification of Immune Cells and Key Genes associated with Alzheimer's Disease
}

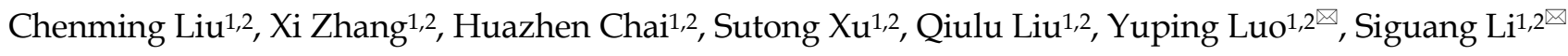 \\ 1. Key Laboratory of Spine and Spinal Cord Injury Repair and Regeneration of Ministry of Education, Orthopedic Department of Tongji Hospital, Tongji \\ University School of Medicine, Shanghai, China. \\ 2. Stem Cell Translational Research Center, Tongii Hospital, Tongji University School of Medicine, Shanghai, China. \\ $凶$ Corresponding authors: Yuping Luo, E-mail: luoyuping@163.com; Siguang Li, E-mail: siguangli@163.com. \\ (c) The author(s). This is an open access article distributed under the terms of the Creative Commons Attribution License (https://creativecommons.org/licenses/by/4.0/). \\ See http://ivyspring.com/terms for full terms and conditions.
}

Received: 2021.08.27; Accepted: 2021.11.18; Published: 2022.01.01

\begin{abstract}
Alzheimer's disease $(A D)$ is an age-related neurodegenerative disorder characterized by cognitive impairment and memory loss, for which there is no effective cure to date. In the past several years, numerous studies have shown that increased inflammation in $A D$ is a major cause of cognitive impairment. This study aimed to reveal 22 kinds of peripheral immune cell types and key genes associated with $A D$. The prefrontal cortex transcriptomic data from Gene Expression Omnibus (GEO) database were collected, and CIBERSORT was used to assess the composition of 22 kinds of immune cells in all samples. Weighted gene co-expression network analysis (WGCNA) was used to construct gene co-expression networks and identified candidate module genes associated with AD. The least absolute shrinkage and selection operator (LASSO) and random forest (RF) models were constructed to analyze candidate module genes, which were selected from the result of WGCNA. The results showed that the immune infiltration in the prefrontal cortex of $A D$ patients was different from healthy samples. Of all 22 kinds of immune cells, MI macrophages were the most relevant cell type to AD. We revealed 10 key genes associated with $A D$ and $M 1$ macrophages by LASSO and RF analysis, including ARMCX5, EDN3, GPRI 74, MRPL23, RAETIE, RODI, TRAFI, WNT7B, OR4K2 and ZNF543. We verified these 10 genes by logistic regression and k-fold cross-validation. We also validated the key genes in an independent dataset, and found GPRI74, TRAFI, RODI, RAETIE, OR4K2, MRPL23, ARMCX5 and EDN3 were significantly different between the AD and healthy controls. Moreover, in the 5XFAD transgenic mice, the differential expression trends of Wnt7b, Gprl74, Ptbp3, Mrp/23, Armcx5 and Raetle are consistent with them in independent dataset. Our results provided potential therapeutic targets for AD patients.
\end{abstract}

Key words: Alzheimer's Disease, immune infiltration, bioinformatics, key genes

\section{Introduction}

Alzheimer's disease (AD) is one of the most common neurodegenerative diseases with a high prevalence [1], which is currently difficult to cure and imposes a heavy burden on both patients and families [2]. The main clinical manifestations of AD patients are memory loss and cognitive dysfunction, and its pathology is mainly characterized by $A \beta$ deposition [3], tau protein hyperphosphorylation [4], neurofibrillary tangles [5] and an increase in inflammation [6].

A growing evidence suggests that neuroinflammation is a major player in $\mathrm{AD}$ pathology. Microglia and astrocytes are actively involved in the immune response of the Central Nervous System (CNS) [7, 8]. During the development of $\mathrm{AD}$, microglia enter an activated state [9], which may affect neuronal apoptosis and the maintenance of synaptic plasticity [10]. Activated microglia internalize pathogenic substances in the brain through cytosolic drinking, phagocytosis or receptormediated endocytosis [11-13]. However, microglia in the aging brain are subject to dysfunction or persistent activation [14-16], which usually leads to an exacerbation of AD pathology. Transcriptome studies have revealed that activated astrocytes also exist in $\mathrm{AD}$ [17]. It has been proposed that inflammatory 
injury induces the A1 astrocyte through the NF-KB pathway. What's more, astrocytes of the A1 phenotype can express inflammatory mediators [18]. The homeostatic function of astrocytes is affected in in neurodegenerative disorders which induces the death of neurons and oligodendrocytes [19]. Moreover, activated microglia and astrocytes could interact and promote neurodegeneration [20].

Several recent studies have highlighted the close association of $\mathrm{AD}$ and peripheral inflammation [21]. For example, the presence of pro-inflammatory cytokines may increase the probability of $\mathrm{AD}$ in obese people [22], and obesity has been listed as one of the risk factors for $\mathrm{AD}[23,24]$. Strong evidence showed that type II diabetes increases the risk of AD [25]. Moreover, peripheral immune cells, including macrophages, natural killer (NK) cells and neutrophils, are actively involved in the pathological response to $\mathrm{AD}$ [26]. Monocyte chemokine receptors, such as CXCL1, are more highly expressed in AD patients [27]. And neutrophils can enter the CNS of $\mathrm{AD}$ mice and surround $\mathrm{A} \beta$ plaques via neutrophil extracellular traps [28], which may lead to increased neuroinflammation [29]. In addition, $\mathrm{T}$ regulatory cells (TRegs) are at high peripheral level in AD patients [30], and the increase of TRegs could be beneficial to $\mathrm{AD}$ patients, which affect microglia responses [31]. In conclusion, immune cells are involved in the occurrence of $\mathrm{AD}$. The molecular



Figure 1. Flow chart of this study. GEO: Gene Expression Omnibus, AD: Alzheimer's Disease, WGCNA: weighted gene co-expression network analysis, LASSO: least absolute shrinkage and selection operator, RF: random forest, ROC: receiver operating characteristic. mechanisms between immune cells and the occurrence of AD needs to be further investigated.

In this study, we explored the relationship between immune cells and $\mathrm{AD}$ and identified AD-associated key genes by a range of bioinformatics methods. We revealed the alteration of immune infiltration of AD pathology, explored AD-associated immune cells, and identified AD-related key genes which affected the occurrence and development of AD. Our results refined the current knowledge on immune infiltration of AD pathology and provided a valuable resource for future studies on immunerelated signaling pathways in AD.

\section{Methods and Materials}

\section{Data preprocessing and immune cell evaluation}

As shown in Figure 1, we first downloaded the GSE33000 dataset from Gene Expression Omnibus (GEO) database. The dataset including 310 samples from the prefrontal cortex of $\mathrm{AD}$ patients and 157 samples from healthy controls. We used R software to process the raw data of the GSE33000 dataset. Then the raw matrix was normalized by the limma package (version 3.46.0) [32]. CIBERSORT was performed to identify the composition of 22 immune cells from gene expression profiles [33]. If the immune cell type is not detected in more than half of all samples, this cell type will be excluded. The retained cell types could be detected in most samples. We determined the differential immune cells between two groups ( $p$-value $<0.05)$ by wilcox.test. The level of immune cell infiltration was demonstrated using ggplot2 (version 3.3.3) and pheatmap (version 1.0.12) packages. As for external verification, we downloaded the GSE44770 dataset, which includes 129 AD samples and 101 healthy controls of the prefrontal cortex. The raw data of the GSE44770 dataset were also processed in the same way of GSE33000 dataset.

\section{WGCNA}

Firstly, the raw expression matrix of the dataset was normalized by the limma package, and genes in the top $25 \%$ variance of all samples were screened, then gene co-expression networks were constructed using WGCNA package 
(version 1.70-3) [34]. We first determined an appropriate soft threshold power to achieve a scale-free topology. By calculating the similarity between genes, the coefficient of similarity between genes was obtained, and genes were clustered into different modules and labeled with different colors. We set the minimum number of genes per module to 30. Trait information was based on the outcome of immune infiltration and disease. Correlations between modules and the trait information were calculated through Pearson correlation method. The module with the highest correlation with traits was selected for subsequent analysis. Then we performed further screening based on gene significance (GS) and module importance (MM).

\section{Functional enrichment analysis}

The Kyoto Encyclopedia of Genes and Genomes (KEGG) and Reactome pathway analysis of key module genes were performed by clusterProfiler (version 3.18.1) [35] and ReactomePA [36] (version 1.34.0) packages. The significance criterion was $p$-value $<0.05$.

\section{Construction of models and identification of key genes}

To filter out the key genes, we analyzed the selected candidate module genes using the least absolute shrinkage and selection operator (LASSO) and random forest (RF), which were used to calculate the importance of key genes in the dataset. The "randomForest" (version 4.6-14) and "glmnet" (version 4.1-1) packages were adopted for LASSO and RF analysis [37]. The data were randomly divided into training cohort and test cohort, and the intersection of the two gene lists from the training cohort by LASSO and RF analysis was regarded as the key genes. We used VennDiagram (version 1.6.20) [38] to visualize the intersection of gene lists. The sensitivity and specificity of the model were validated by receiver operating characteristic (ROC) curve using "ROCR" package (version 1.0-11) [39].

\section{Validation of key genes in GEO datasets}

In order to validate the relationship between $\mathrm{AD}$ and key genes, we constructed logistic regression model based on the common genes of the two gene lists in the training cohort. The internal data GSE33000 were randomly grouped according to the test cohort and training cohort 3/7. We generated logistic regression model in the training cohort, and the test cohort was used for verification. The ROC curve of the pROC (version 1.17.0.1) package was used to evaluate the effectiveness of the model [40]. Confusion matrix evaluated the accuracy of the model. In addition, we also use k-fold cross-validation to verify our results.
The samples of the GSE33000 dataset were randomly divided into 10 equal parts, each time 1 of the 10 parts was used as the test cohort, and all the others were used as the training cohort. The maximum test cohort accuracy and training cohort accuracy were found for ten cross-validations, the fold corresponding to the maximum accuracy was used as the test cohort and the rest as the training cohort. The ROC and confusion matrix were also used to evaluate the effectiveness of the model in the test and training cohort. We also verified the relative expression levels of key genes in the GSE44770 dataset. The ggboxplot was used to display the relative expression levels of key genes in the $\mathrm{AD}$ and control groups. We used T-test for statistical analysis between two groups. The significance criterion was $p$-value $<0.05$.

\section{Animals}

5.5-month-old heterozygous 5XFAD mice (on a C57BL/6N background) overexpress mutant human amyloid beta (A4) precursor protein 695 (APP) with the Swedish (K670N, M671L), Florida (I716V), and London (V717I) Familial Alzheimer's Disease (FAD) mutations along with human presenilin 1 (PS1) harboring two FAD mutations, M146L and L286V. Both transgenes are regulated by the mouse Thy1 promoter to drive overexpression in the brain [41]. The mice are kept in Tongii University Animal Center with constant temperature and humidity, light and dark cycle for $12 \mathrm{~h}$. The control group and the $\mathrm{AD}$ group consist of two male mice and two female mice, respectively.

\section{RNA extraction and quantitative real time-PCR}

We extract RNA from the prefrontal cortex of all mice by RNAiso Plus (9109, TaKaRa, Dalian, China) following the manufacturer's instructions. Quantitative real-time PCR was carried out using the AceQ Universal SYBR qPCR Master Mix (Q411, Vazyme, Biotech, Nanjing, China). Relative expression levels of genes were calculated by $\Delta \Delta \mathrm{Ct}$ method and normalized to $\beta$-Actin and compared with control samples. All sequences for RNA primers are shown in Table 1.

\section{Statistical analysis}

All data are presented as mean \pm standard deviation (SD). Each experiment was replicated at least three times. Data visualization and analysis were performed with GraphPad Prism 8 (GraphPad Software Inc., La Jolla, CA, USA). Statistical analysis was performed using student's t-test. 
Table 1. Lists of primer sequences used for quantitative real-time PCR

\begin{tabular}{|c|c|}
\hline Genes & Sequences \\
\hline \multirow[t]{2}{*}{$\beta$-Actin } & Forward: CTAAGGCCAACCGTGAAAAG \\
\hline & Reverse: ACCAGAGGCATACAGGGACA \\
\hline \multirow[t]{2}{*}{ Ptbp3 } & Forward: CTCGCTTAGACCTTCCTACTGG \\
\hline & Reverse: CTGCTTGAGGAAATGCGATGGC \\
\hline \multirow[t]{2}{*}{ Mrpl23 } & Forward: GTTTGCGGGACACCGAAAG \\
\hline & Reverse: CCACCCAGTTGGTAAAGGGG \\
\hline \multirow[t]{2}{*}{ Armex5 } & Forward: AAGAGCGCAGGTCCAACTTC \\
\hline & Reverse: AGTCATTCAGCCCCTTTCCA \\
\hline \multirow[t]{2}{*}{ Wnt7b } & Forward: ATGAGGACATGGGACCCTCA \\
\hline & Reverse: AGCCCTGGCAGTTTCTTACC \\
\hline \multirow[t]{2}{*}{ Edn3 } & Forward: GCTGCACGTGCTTCACTTAC \\
\hline & Reverse: GCTGGGAGCTTTCTGGAACT \\
\hline \multirow[t]{2}{*}{ Raet1e } & Forward: ATCCTACCTCAGCAGACCTTC \\
\hline & Reverse: TGGTGTTAGACACCTTGTCCC \\
\hline \multirow[t]{2}{*}{ Gpr174 } & Forward: TCTCCAAGGTAAGTGGTGCC \\
\hline & Reverse: TGGCTGCTGGAATGATCCAC \\
\hline \multirow{2}{*}{ Traf1 } & Forward: GCCCTGGACTGAGTTCCTATG \\
\hline & Reverse: GAGGGGGACCCTGGGTATT \\
\hline
\end{tabular}

\section{Results}

\section{Immune infiltration was altered in the prefrontal cortex of AD patients}

GSE33000 dataset include 310 AD samples and

A
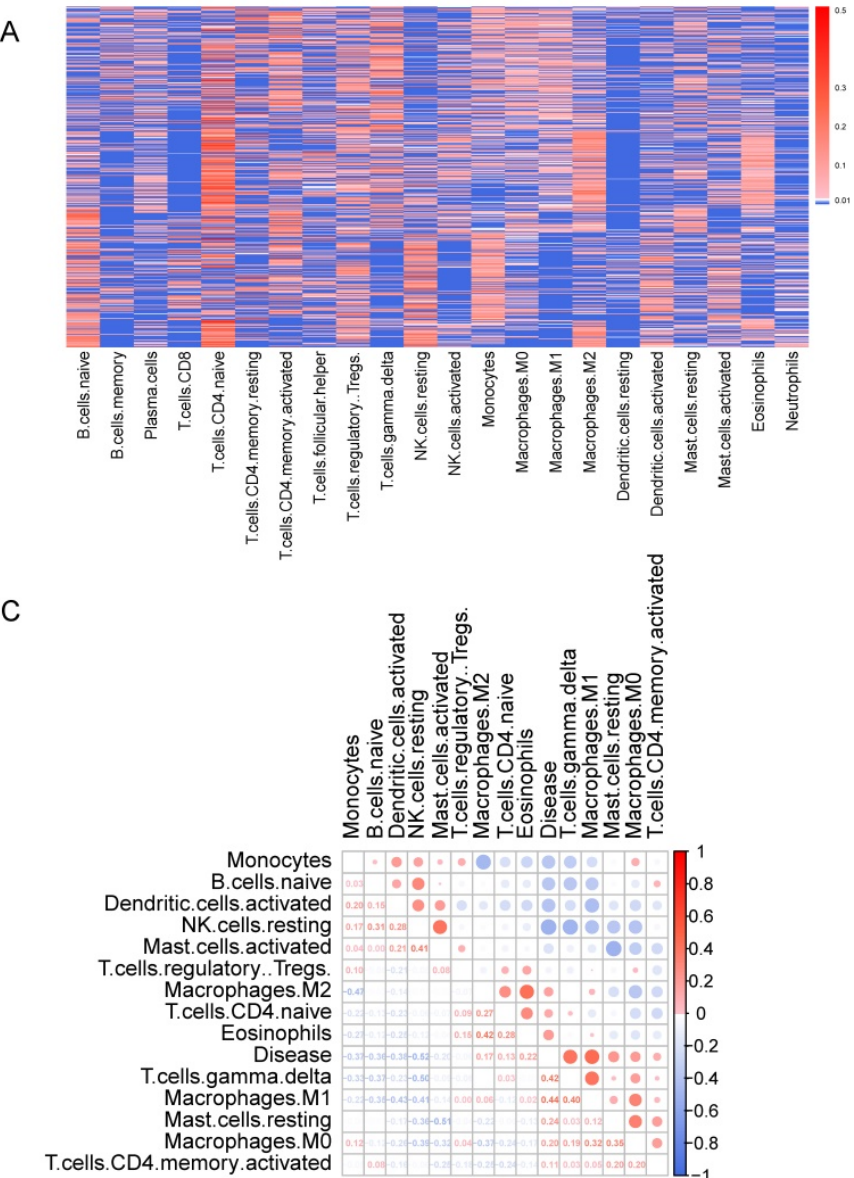

157 healthy samples from the prefrontal cortex. CIBERSORT was performed to obtain the relative composition of 22 kinds of immune cells (Figure 2A). The composition of the 22 kinds of immune cells was shown in Figure 2B, and the immune infiltration was different in $\mathrm{AD}$ and healthy samples. As described in materials and methods, we found 8 cell types, memory B cells, resting dendritic cells, neutrophils, activated NK cells, plasma cells, resting memory CD4 $\mathrm{T}$ cells, CD8 T cells and follicular helper T cells were not detected in more than half of all samples, so we excluded these cell types, and the remained 14 cell types were used for subsequent analyses. Pearson correlation coefficients were used to calculate the correlation of the 14 immune cell types with AD. As shown in Figure 2C, M2 macrophages, CD4 naive T cells, regulatory $\mathrm{T}$ cells, eosinophils, gamma delta $\mathrm{T}$ cells, M1 macrophages, resting mast cells, M0 macrophages and activated CD4 memory $\mathrm{T}$ cells are positively correlated with AD.



Figure 2. Immune Infiltration Analysis. (A) Heatmap showed the composition of 22 kinds of immune cells in each sample. The relative composition was higher from blue to red. Each row in the heatmap was a sample. (B) Boxplot of the composition of immune cells. (C) Correlation matrix of 14 immune cells and disease. Red represents positive correlation, and blue represents negative correlation. 
A

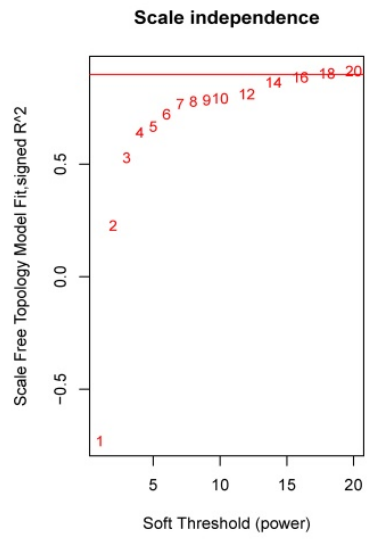

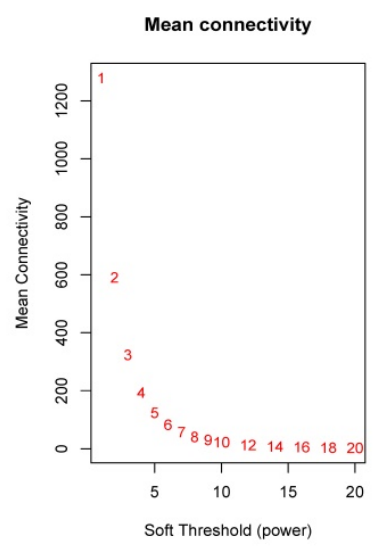

B



C

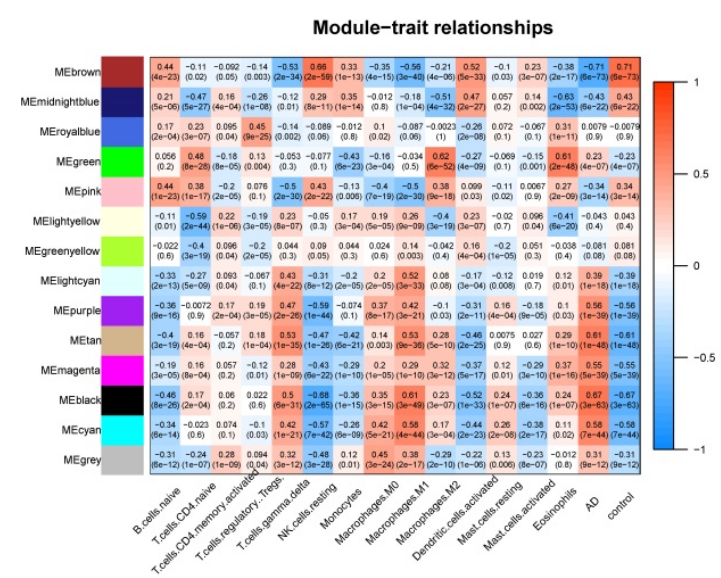

D



Figure 3. WGCNA revealed gene co-expression networks and module-trait relationships. (A) Selecting the best soft threshold power $\beta$. (B) Dendrogram of top $25 \%$ variance genes. (C) The heatmap of module-trait relationships. The black module had the strongest correlation with M1 macrophages. (D) The scatterplot of gene significance (GS) against module membership (MM) in the black module.

\section{M1 macrophages were highly associated with AD}

WGCNA was utilized to analyze the co-expression networks associated with immune cells in AD. We normalized the data of the GSE33000 dataset and subsequently screened the genes with the top $25 \%$ variance, and 4142 genes which meet the requirement were obtained. Then we chose soft threshold power $\beta=14$ to build a scale-free co-expression network, the scale-free $\mathrm{R}^{2}>0.85$ (Figure $3 \mathrm{~A})$. Based on the similarity between genes, the 4142 genes were clustered into 14 different color modules (Figure 3B, 3C). Correlation analysis was performed between modules, the 14 retained immune cell types and disease status. The module exhibiting highest positive correlation with AD was black module, which contain 336 co-expression genes, and the immune cell exhibiting highest positive correlation with black module was M1 macrophages (Figure 3C), suggesting M1 macrophages were highly associated with AD.

\section{Genes in black module were mainly affect nucleotide excision repair, ion transport and Hedgehog signaling pathway}

To further explore the potential biological pathways and processes about the black module genes, we performed KEGG and Reactome functional annotation analyses based on 336 black module genes (Figure 4A, 4B). The results of KEGG pathway analysis showed that black module genes were significantly enriched in nucleotide excision repair, Hepatitis B, Hedgehog signaling pathway and ABC transporters. The results of Reactome pathway analysis suggested that black module genes were mainly enriched in Transcription-Coupled Nucleotide Excision Repair (TC-NER), Synthesis of active ubiquitin: roles of E1 and E2 enzymes, Programmed Cell Death, Organic anion transporters, Intrinsic Pathway for Apoptosis, Hedgehog 'on' state, Cell death signaling via NRAGE, NRIF and NADE, Apoptosis. Based on the p-value and frequency of each term, these results suggested that the black module genes mainly affect nucleotide excision 
repair, ion transport and Hedgehog signaling pathway.

\section{Identification and validation of 10 genes associated with $M 1$ macrophages and AD in GEO datasets}

As the WGCNA results demonstrated, black module was the key module associated with M1 macrophages and AD. Based on the cut-off criteria $(|\mathrm{MM}|>0.8$ and $|\mathrm{GS}|>0.2), 242$ genes with high

A

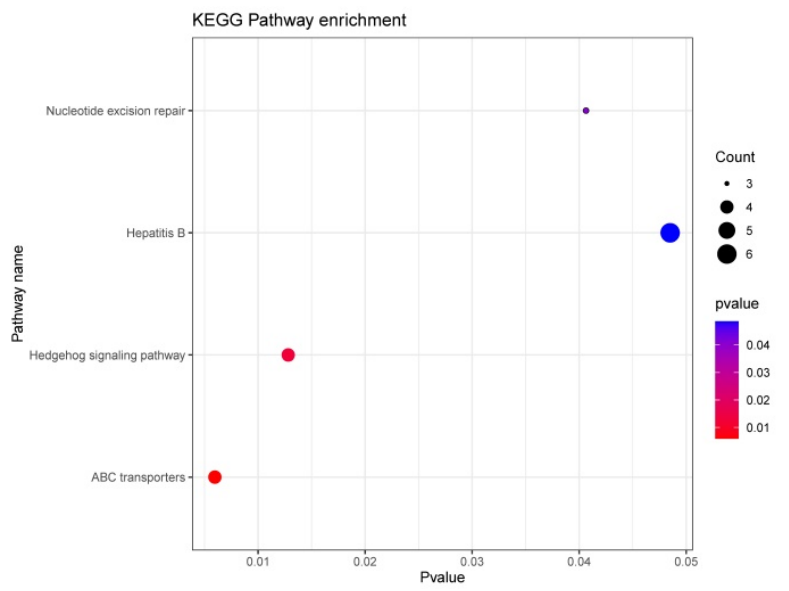

connectivity in the black module were selected for the LASSO and RF analysis (Figure 3D). According to the relationship between mean square error of cross-validated and model size, we generated the LASSO regression model based on the 1-se criteria (Figure 5A). The 1-se gives a model with excellent performance and a minimum number of independent variables, at which point 31 non-zero variables are retained. Table 2 showed the estimated coefficients between the LASSO regressions of genes screened by

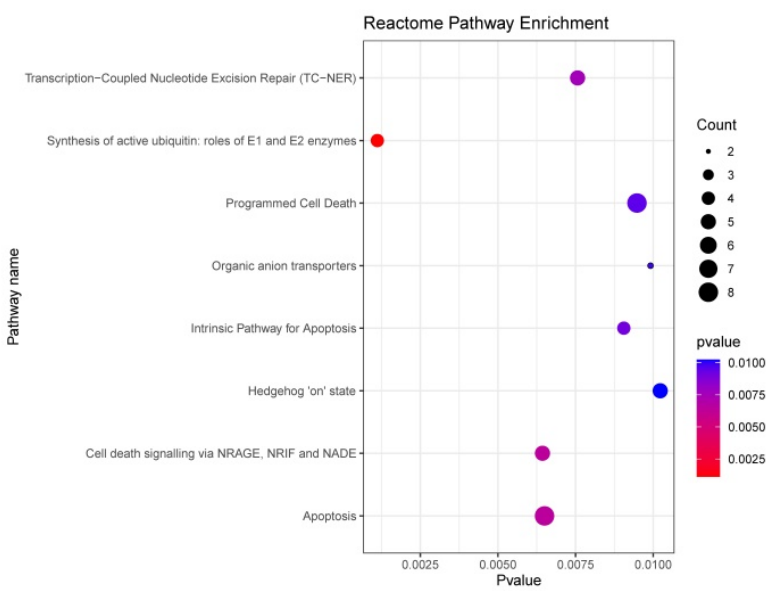

Figure 4. Functional Enrichment Analysis. (A) KEGG enrichment analysis of black module genes. (B) Reactome enrichment analysis of black module genes.

A

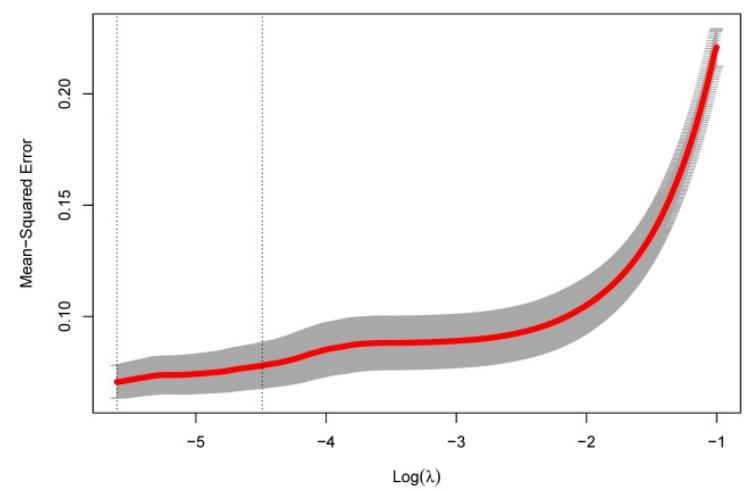

C

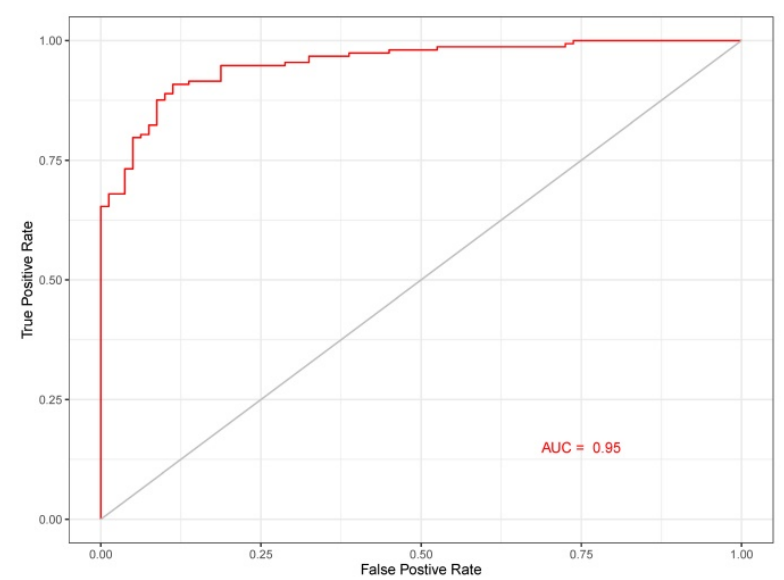

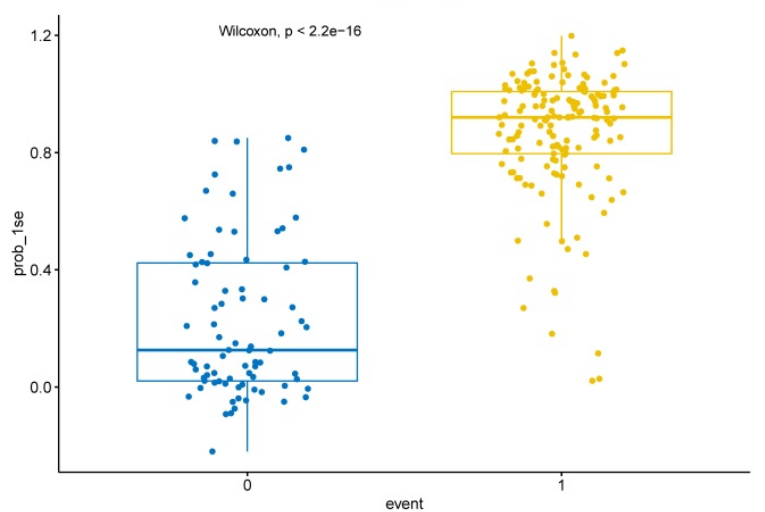

Figure 5. Identification and verification 31 genes in the LASSO model. (A) The partial likelihood deviance for the lasso regression. $\lambda$ is the tuning parameter. (B) The LASSO model between AD samples and control samples in the test cohort. (C) ROC curve verified the effectiveness of LASSO model in the test cohort. 
the black module and AD. As a result, 31 key genes were identified by LASSO analysis. What's more, the LASSO model based on expression levels of these genes was also different in $\mathrm{AD}$ and control in the test cohort (Figure 5B). Then we performed ROC curve in the test cohort to evaluate the effectiveness of the LASSO regression model. The area under the curve (AUC) was 0.95 (Figure 5C). The top 30 genes based on the parameter of increase in node purity in RF analysis were used for subsequence analysis (Figure 6A, Table 3). The RF model based on expression levels of the candidate genes was also different in $\mathrm{AD}$ and control samples in the test cohort (Figure 6B). The AUC of the RF model in the test cohort was 0.935 (Figure 6C). These all proved that our models were reliable for identifying genes which affect the occurrence of AD. Therefore, we defined the common genes of the two gene lists identified by random forest and LASSO regression respectively, as the key genes associated with M1 macrophages and AD (Figure 7A). Then correlation analysis showed 10 genes were key genes associated with $\mathrm{M} 1$ macrophages and $\mathrm{AD}$, of which ARMCX5, EDN3, GPR174, MRPL23, RAET1E, ROD1, TRAF1 and WNT7B were positively associated with M1 macrophages and $\mathrm{AD}$, while OR4K2 and ZNF543 were negatively associated with M1 macrophages and AD (Figure 7B).

Table 2. The estimated coefficients for logistic least absolute shrinkage and selection operator (LASSO) regression between genes screened by the black module and $A D$

\begin{tabular}{|c|c|}
\hline Variables & Coefficients \\
\hline AARS & 0 \\
\hline AASS & 0 \\
\hline ABCB10 & 0 \\
\hline ABCC12 & 0 \\
\hline ABHD1 & 0 \\
\hline ABHD10 & 0 \\
\hline ACBD7 & 0 \\
\hline ADAM22 & 0 \\
\hline ADAM9 & 0 \\
\hline ADAMDEC1 & 0 \\
\hline DCY7 & 0 \\
\hline AMOTL1 & 0 \\
\hline AMPD1 & 0 \\
\hline $\mathrm{AOC} 2$ & 0 \\
\hline APAF1 & 0 \\
\hline APIP & 0 \\
\hline ARIH2 & 0 \\
\hline ARMC7 & 0 \\
\hline ARMCX5 & 0.111768 \\
\hline C11orf40 & 0.13664 \\
\hline C1orf170 & 0 \\
\hline C21orf56 & 0 \\
\hline C6orf27 & 0.031063 \\
\hline C7orf21 & 0 \\
\hline C9orf21 & 0 \\
\hline C9orf52 & 0 \\
\hline C9orf75 & 0 \\
\hline CARD14 & 0 \\
\hline CASP2 & 0 \\
\hline CCDC15 & 0 \\
\hline CCDC50 & 0 \\
\hline
\end{tabular}

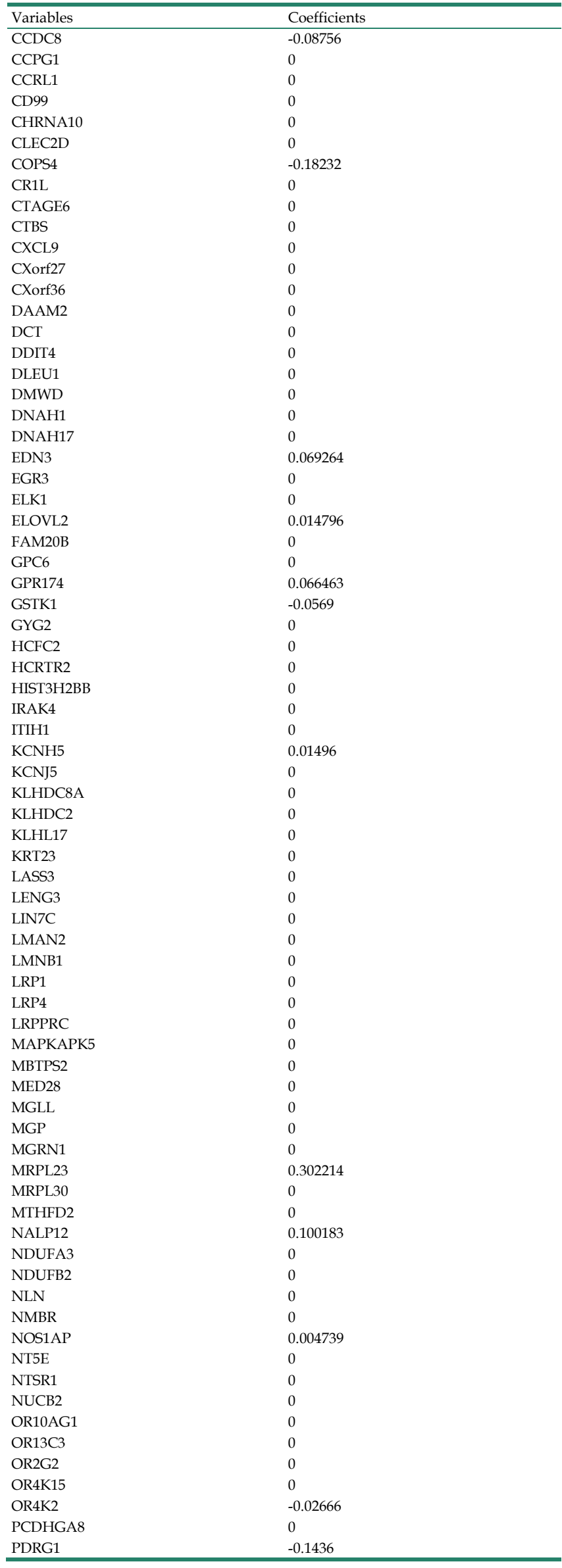




\begin{tabular}{|c|c|}
\hline Variables & Coefficients \\
\hline PDXK & 0 \\
\hline PF4 & 0 \\
\hline PKNOX2 & 0 \\
\hline PMS2L11 & 0 \\
\hline POLR2G & 0 \\
\hline POMT2 & 0 \\
\hline POU6F2 & 0 \\
\hline PPIL2 & 0 \\
\hline PPP1R13B & 0 \\
\hline PPP4R1L & 0 \\
\hline PRR10 & 0 \\
\hline PSMA5 & 0 \\
\hline PTPLA & 0 \\
\hline PXDN & 0 \\
\hline PZP & 0 \\
\hline RAB12 & 0 \\
\hline RAB17 & 0 \\
\hline RABAC1 & 0 \\
\hline \multicolumn{2}{|l|}{ RACGAP1P } \\
\hline RAET1E & 0.238109 \\
\hline RAMP1 & 0 \\
\hline RAPGEF1 & 0 \\
\hline RER1 & 0 \\
\hline RET & 0 \\
\hline RFC2 & 0 \\
\hline RGS21 & 0 \\
\hline RHBDD1 & 0.047236 \\
\hline RIC8A & 0 \\
\hline RNF170 & 0 \\
\hline ROD1 & 0.19671 \\
\hline ROS1 & 0 \\
\hline RSAD1 & 0 \\
\hline RTP2 & 0 \\
\hline STAT2 & 0 \\
\hline SCP2 & 0 \\
\hline SEC61B & 0 \\
\hline SEH1L & 0 \\
\hline SENP8 & 0 \\
\hline \multicolumn{2}{|l|}{ SERPINA13 } \\
\hline SETD7 & 0 \\
\hline SFTPA1 & 0 \\
\hline SGTB & 0 \\
\hline \multicolumn{2}{|l|}{ SH3BGRL3 } \\
\hline OSHF & -0.16311 \\
\hline \multicolumn{2}{|l|}{ SLC17A5 } \\
\hline \multicolumn{2}{|l|}{ SLC23A2 } \\
\hline SLC25A22 & 0 \\
\hline SLC30A4 & 0 \\
\hline SLC35B4 & 0 \\
\hline SLC39A3 & 0 \\
\hline SLC3A1 & 0 \\
\hline SLC4A11 & 0 \\
\hline SLC6A14 & 0 \\
\hline SLCO1A2 & 0 \\
\hline SLCO2A1 & 0 \\
\hline SLITRK4 & 0 \\
\hline SMAD9 & 0 \\
\hline SMCHD1 & 0 \\
\hline SMCR2 & 0 \\
\hline SMOC2 & 0 \\
\hline SMPDL3B & 0 \\
\hline SOD3 & 0 \\
\hline SORCS1 & 0 \\
\hline SOX5 & 0 \\
\hline SPIB & 0 \\
\hline STAMBP & 0 \\
\hline SUFU & 0 \\
\hline SULT1C1 & 0 \\
\hline SYNPO & -0.16448 \\
\hline SYT10 & 0 \\
\hline SYT15 & 0 \\
\hline TAL1 & 0 \\
\hline TAS1R1 & 0.20351 \\
\hline
\end{tabular}

\begin{tabular}{|c|c|}
\hline Variables & Coefficients \\
\hline TBC1D20 & 0 \\
\hline TBC1D19 & 0 \\
\hline TBCD & 0 \\
\hline TESC & 0.304705 \\
\hline THAP9 & 0 \\
\hline TICAM1 & 0 \\
\hline TLK1 & 0 \\
\hline TMC4 & 0 \\
\hline TMEM116 & 0 \\
\hline TMEM131 & 0 \\
\hline TMEM16K & 0 \\
\hline TMEM47 & 0 \\
\hline TMEM80 & 0 \\
\hline TMEM93 & 0 \\
\hline TMPO & 0 \\
\hline TNFAIP3 & 0 \\
\hline TNFRSF8 & 0 \\
\hline TNFSF18 & 0 \\
\hline TNK1 & 0 \\
\hline TNRC18 & 0 \\
\hline TP53I13 & 0 \\
\hline TRAF1 & 0.414105 \\
\hline TRAT1 & 0 \\
\hline TRIM8 & 0 \\
\hline TRO & 0 \\
\hline TRPS1 & 0 \\
\hline TSPAN13 & -0.15952 \\
\hline TSPAN18 & 0 \\
\hline TSSK6 & 0 \\
\hline TSTA3 & 0 \\
\hline TTC5 & 0 \\
\hline TUBGCP5 & 0 \\
\hline TUSC3 & 0 \\
\hline TXK & 0 \\
\hline TXNIP & 0 \\
\hline UBAP2 & 0 \\
\hline UBE2E4P & 0 \\
\hline UBE2G1 & -0.13186 \\
\hline UBE2W & 0 \\
\hline UCP1 & 0 \\
\hline UNC119 & 0 \\
\hline UPF2 & 0 \\
\hline USP53 & 0 \\
\hline WDR48 & 0 \\
\hline WDR52 & 0 \\
\hline WIPI1 & 0 \\
\hline WNT7B & 0.092085 \\
\hline WSB1 & 0 \\
\hline XPO4 & 0 \\
\hline YWHAQ & -0.01995 \\
\hline ZBTB34 & 0 \\
\hline ZCWPW2 & 0 \\
\hline ZMYND15 & -0.04248 \\
\hline ZNF132 & 0 \\
\hline ZNF157 & 0 \\
\hline ZNF238 & 0 \\
\hline ZNF253 & 0 \\
\hline ZNF256 & 0 \\
\hline ZNF30 & 0 \\
\hline ZNF365 & 0 \\
\hline ZNF45 & -0.08238 \\
\hline ZNF543 & -0.09474 \\
\hline ZNF584 & 0 \\
\hline ZNF652 & 0 \\
\hline ZРBP2 & 0.097042 \\
\hline
\end{tabular}

To validate the 10 genes associated with the occurrence of $\mathrm{AD}$, we constructed logistic regression model based on the expression matrix of 10 key genes associated with $\mathrm{AD}$ in the training cohort, and validated them in the test cohort by ROC curve (AUC 
$=0.961,95 \% \mathrm{CI}=0.933-0-990)$ (Figure 8A). In addition, we also validated the genes using 10-fold cross-validation, we evaluated the model in the test and training cohort by ROC curve. For the 10-fold cross-validation, both the test $(\mathrm{AUC}=0.941,95 \% \mathrm{CI}=$ $0.862-1)$ and training cohort $(\mathrm{AUC}=0.875,95 \% \mathrm{CI}=$ 0.840-0.910) showed relatively good performance (Figure 8B-C). We also evaluated the models by confusion matrix in the test and training cohort (Figure 8D-F), the accuracy and recall of the models

A

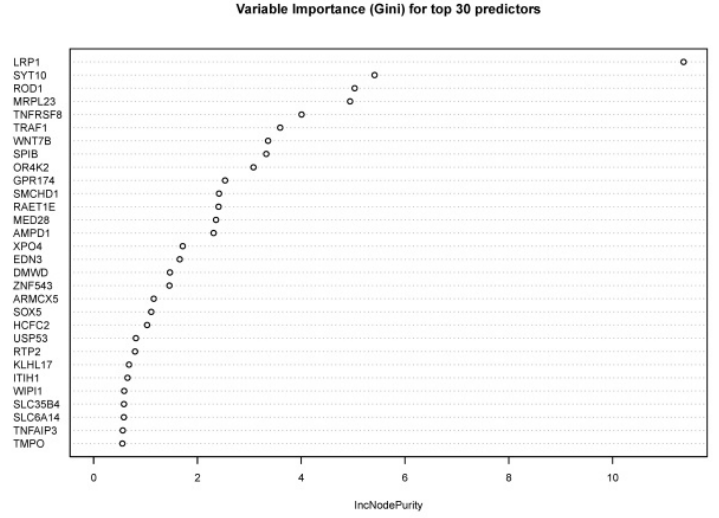

C

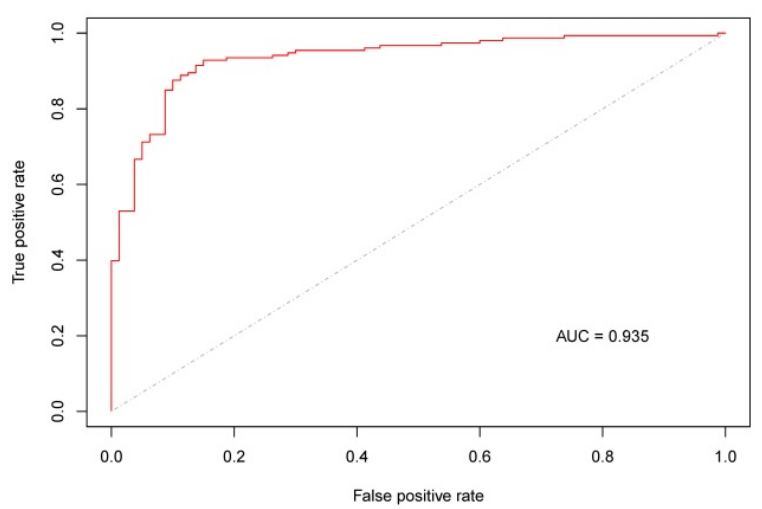

based on the confusion matrix of the test cohort and training cohort were shown in Table 4. All of these results showed that these genes were the key genes associated with the occurrence of AD. GSE44770 dataset was used as an independent dataset to verify the relative expression of 10 key genes in $\mathrm{AD}$ and healthy controls. We found that GPR174, TRAF1, ROD1, RAET1E, OR4K2, MRPL23, ARMCX5 and $E D N 3$ were differentially expressed between the AD and healthy controls $(p<0.05)$ (Figure 9A-J).

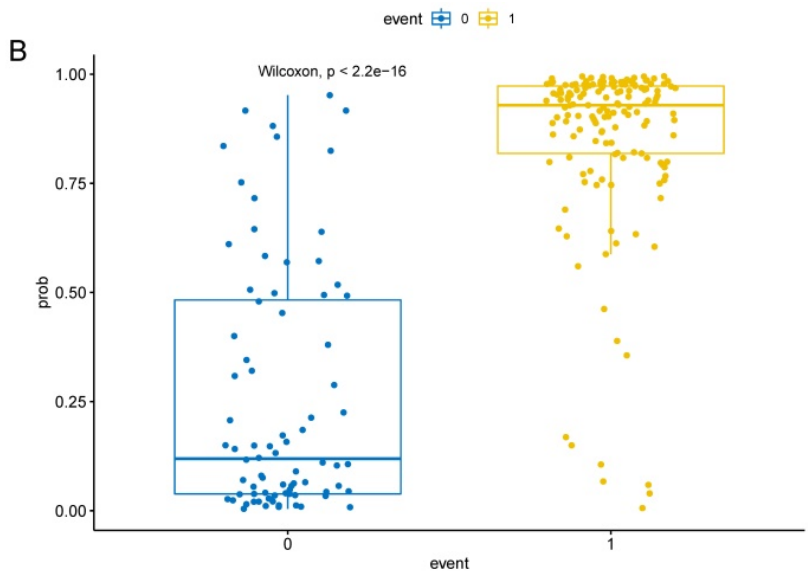

Figure 6. Identification and verification $\mathbf{3 0}$ genes in the $\mathbf{R F}$ model. (A) Top 30 genes based on variable importance in $\mathrm{RF}$ analysis. (B) The RF model between $A D$ samples and control samples in the test cohort. (C) ROC curve of RF model in the test cohort.

A

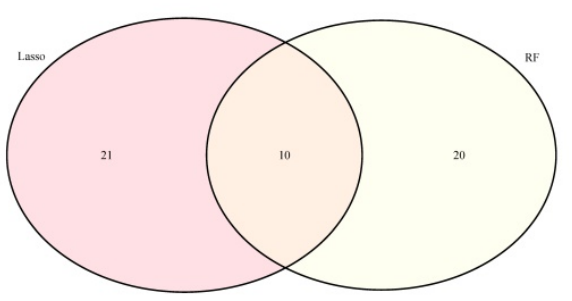

\begin{tabular}{|c|c|c|c|c|c|c|c|c|c|c|}
\hline $\begin{array}{c}0.69 \\
\text { (le-66) }\end{array}$ & $\begin{array}{c}0.70 \\
(9 \mathrm{e}-66)\end{array}$ & $\begin{array}{c}0.68 \\
(1 \mathrm{e}-63)\end{array}$ & $\begin{array}{c}0.73 \\
(8 \mathrm{e}-80)\end{array}$ & $\begin{array}{c}-0.68 \\
(10-64) \\
\end{array}$ & $\begin{array}{c}0.64 \\
(66-56)\end{array}$ & $\begin{array}{l}0.71 \\
(5 \mathrm{e}-72)\end{array}$ & $\begin{array}{c}0.74 \\
\text { (1e-82) } \\
\end{array}$ & $\begin{array}{r}0.68 \\
(2 e-64) \\
\end{array}$ & $\begin{array}{c}-0.72 \\
(10 \mathrm{e}-77) \\
\end{array}$ & $A D$ \\
\hline $\begin{array}{c}0.52 \\
(4 \mathrm{e}-34)\end{array}$ & $\begin{array}{c}0.56 \\
(2 \mathrm{e}-40)\end{array}$ & $\begin{array}{c}0.60 \\
(2 \mathrm{e}-47)\end{array}$ & $\begin{array}{c}0.53 \\
(4 \mathrm{e}-35)\end{array}$ & $\begin{array}{c}-0.55 \\
(4 \mathrm{c}-38)\end{array}$ & $\begin{array}{c}0.60 \\
(7 \mathrm{e}-47)\end{array}$ & $\begin{array}{l}0.55 \\
\text { (le-38) }\end{array}$ & $\begin{array}{l}0.54 \\
(60-377\end{array}$ & $\begin{array}{c}0.58 \\
(22-43)\end{array}$ & $\begin{array}{c}-0.51 \\
(7 \mathrm{e}-34)\end{array}$ & Macrophages.M1 \\
\hline  & 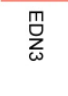 & $\begin{array}{l}\frac{Q}{0} \\
\underset{D}{D}\end{array}$ & 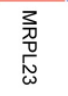 & $\begin{array}{l}\text { 임 } \\
\text { 弆 }\end{array}$ & $\begin{array}{l}\text { 㖇 } \\
\text { 而 }\end{array}$ & $\begin{array}{l}\text { Dू } \\
\text { 모 }\end{array}$ & 分 & 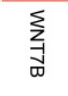 & $\begin{array}{l}\underset{N}{N} \\
\text { 省 } \\
\text { L }\end{array}$ & \\
\hline
\end{tabular}

Figure 7. Correlation analysis of key genes with MI macrophage and AD. (A) Venn diagram of the 10 communal key genes between Lasso and RF analysis. (B) The correlations between the common genes respectively identified by LASSO and RF analysis and MI macrophage and AD. Blue represents negative correlation, and red represents positive correlation. 

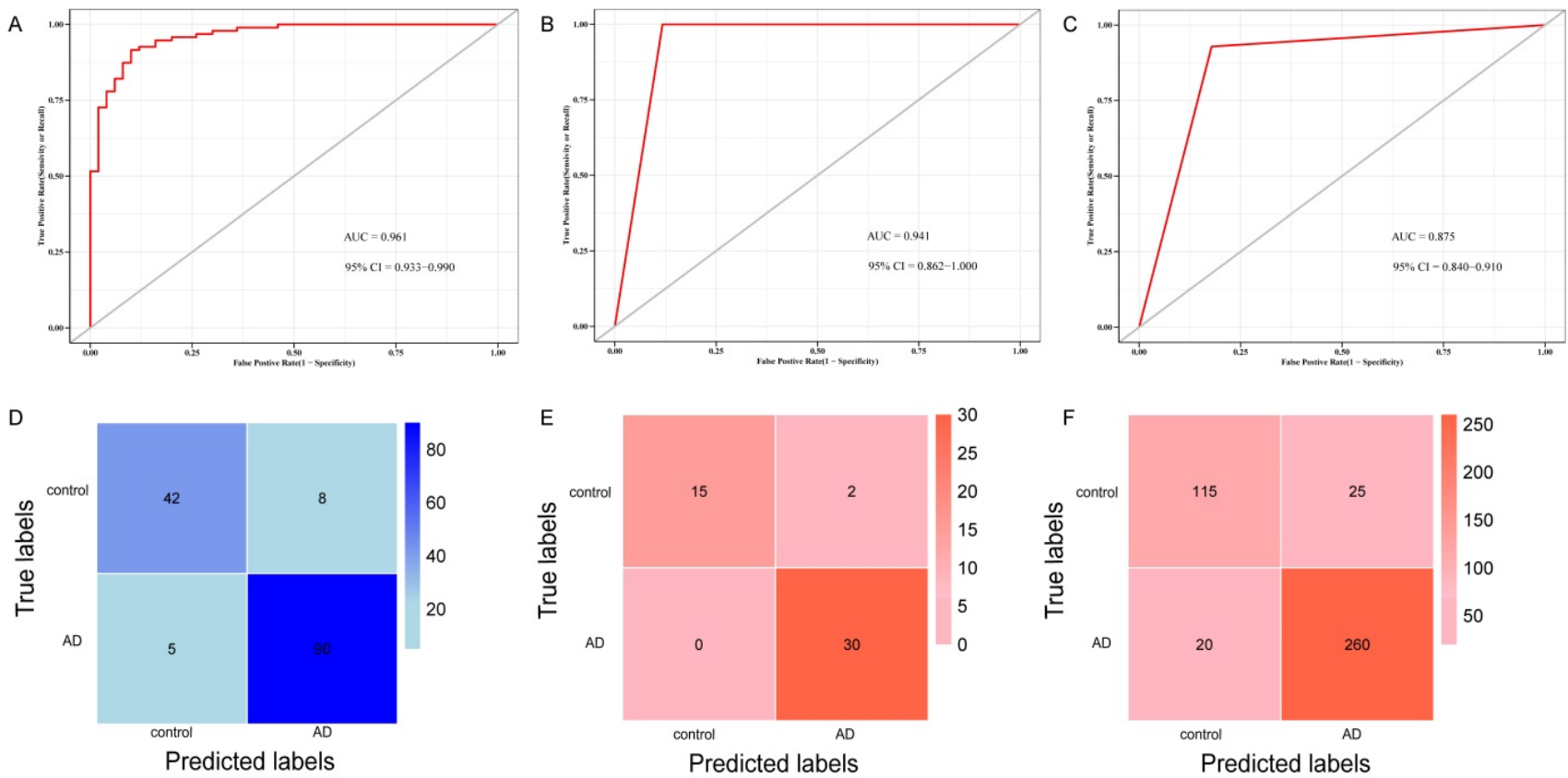

Figure 8. ROC curve and confusion matrix of logistic model and k-fold cross-validation based on key genes. (A) ROC curve for distinguishing AD from control in the test cohort of logistic model. (B) ROC curve for distinguishing AD from control in the test cohort of the k-fold cross-validation. (C) ROC curve for differentiating AD from control in training cohort of the k-fold cross-validation. (D) Confusion matrix of the logistic regression model in test cohort. (E) Confusion matrix of the k-fold cross-validation in test cohort. (F) Confusion matrix of the k-fold cross-validation in training cohort.

Table 3. The parameter of increase in node purity of top 30 gene based on RF analysis

\begin{tabular}{ll}
\hline & IncNodePurity \\
\hline LRP1 & 11.36755 \\
SYT10 & 5.41367 \\
ROD1 & 5.029577 \\
MRPL23 & 4.94144 \\
TNFRSF8 & 4.006692 \\
TRAF1 & 3.594842 \\
WNT7B & 3.361917 \\
SPIB & 3.326772 \\
OR4K2 & 3.080312 \\
GPR174 & 2.533245 \\
SMCHD1 & 2.416868 \\
RAET1E & 2.407908 \\
MED28 & 2.358533 \\
AMPD1 & 2.312181 \\
XPO4 & 1.717311 \\
EDN3 & 1.659224 \\
DMWD & 1.470659 \\
ZNF543 & 1.461082 \\
ARMCX5 & 1.15924 \\
SOX5 & 1.110552 \\
HCFC2 & 1.031185 \\
USP53 & 0.814927 \\
RTP2 & 0.798482 \\
KLHL17 & 0.682118 \\
ITIH1 & 0.653343 \\
WIPI1 & 0.588846 \\
SLC35B4 & 0.584705 \\
SLC6A14 & 0.582928 \\
TNFAIP3 & 0.562013 \\
TMPO & 0.554761 \\
\hline &
\end{tabular}

Seven key homologous genes associated with human $A D$ are differentially expressed between 5XFAD models and wild type mice

In addition to validating our results in an independent dataset, we also validated the common gene list of LASSO and RF analysis in the 5XFAD model. Since ZNF543 and OR4K2 have no homologs in mice, we examined the relative mRNA levels of the remaining 8 genes in mice. As illustrated in Figure 10, compared to the control group, the relative mRNA levels of Traf1 and Raet1e were significantly increased compared to the control group $(P<0.05)$ and the AD group showed significantly decreased mRNA levels of Wnt7b, Gpr174, Ptbp3, Mrpl23 and Armcx5. Among them, the differential expression trends of $W n t 7 b$, Gpr174, Ptbp3, Mrpl23, Armcx5 and Raet1e are consistent with the trends in GSE44770 dataset.

Table 4. The confusion matrix index of logistic regression and k-fold cross-validation

\begin{tabular}{llll}
\hline Index & Logistic regression & \multicolumn{2}{l}{$\mathrm{k}$-fold cross-validation } \\
\cline { 2 - 4 } & test cohort & test cohort & training cohort \\
\hline Precision & 0.8936 & 1 & 0.8519 \\
Recall & 0.8400 & 0.8824 & 0.8241 \\
\hline
\end{tabular}

\section{Discussion}

Microglia are tissue-resident macrophages in the central nervous system that have been shown to be activated in the ADs and close to the site of amyloid deposition [42]. The effects of overactivated microglia on neurons and synapses may be negative. It is now generally accepted that M1 macrophages are thought to actively recruit to inflamed tissues and trigger pro-inflammatory innate immune responses [43]. CD45 hi $\mathrm{Ly}_{6 \mathrm{C}^{+}} \mathrm{CCR}^{+}$monocytes could enter the CNS 
and modulate pathology in the context of disease [44]. It has also been shown that senescent macrophages display a significant reduction in glycolysis and mitochondrial oxidative phosphorylation, which can lead to immune dysfunction [45]. Moreover, curcumin can affect $\mathrm{AD}$ by enhancing macrophage-mediated clearance of $A \beta$ [46]. In the present study, by analyzing the GSE dataset of the GEO database, we determined the putative composition of 22 immune cells in the prefrontal cortex of 310 AD samples and 157 healthy samples. We constructed the co-expression network in that identified 14 different modules and found that the black module was highly associated with M1 macrophages and AD.

A

ZNF543

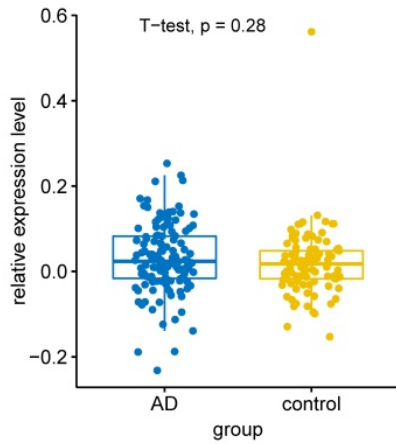

E ROD1

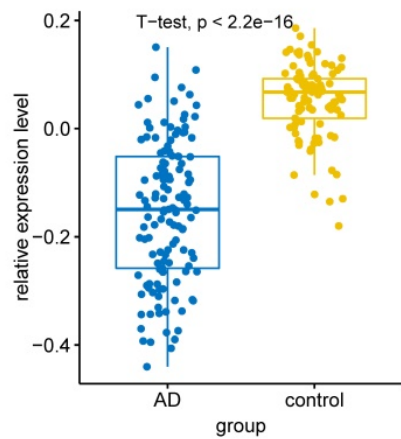

I ARMCX5

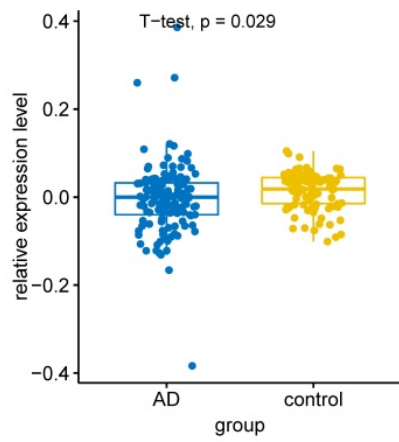

B WNT7B

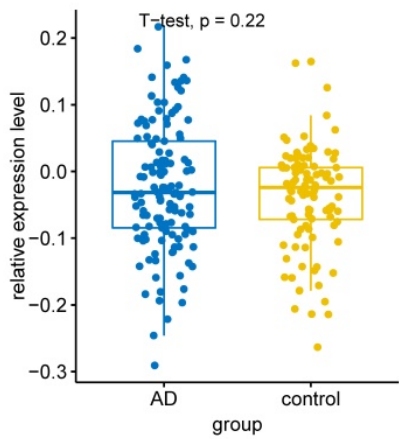

F RAET1E

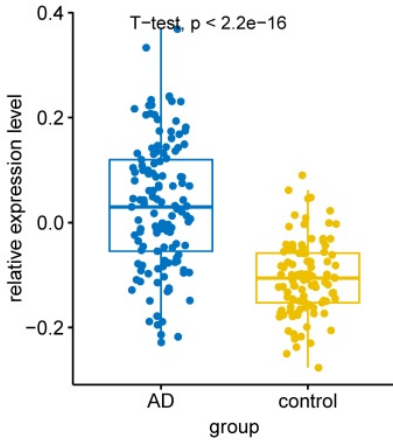

J EDN3

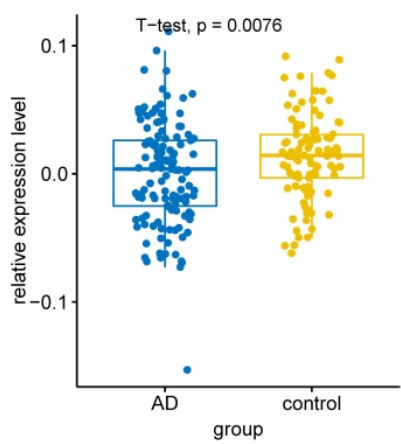

Based on LASSO and RF, we identified 10 hub genes associated with $\mathrm{M} 1$ macrophages and $\mathrm{AD}$, including ARMCX5, EDN3, GPR174, MRPL23, RAET1E, ROD1, TRAF1, WNT7B, OR4K2 and ZNF543. In an independent GSE44770 dataset, GPR174, TRAF1, ROD1, RAET1E, OR4K2, MRPL23, ARMCX5 and EDN3 were significantly different between the AD and healthy controls. We validated the results of bioinformatics analysis in 5XFAD transgenic mice, the relative mRNA levels of Wnt7b, Gpr174, Ptbp3, Mrpl23, Armcx5, Traf1 and Raet1e were significantly different in $\mathrm{AD}$ and control groups. And the differential expression trends of Wnt7b, Gpr174, Ptbp3, Mrpl23, Armcx5 and Raet1e are consistent with bioinformatics

C

GPR174
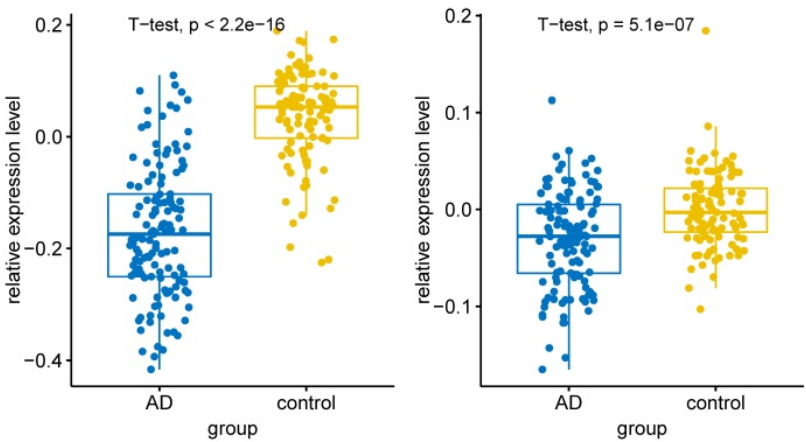

H MRPL23


Figure 9. The relative expression levels of 10 key genes in GSE44770 dataset. (A-J) The boxplot showed the relative expression levels of 10 key genes in AD and healthy controls. 
analysis. At the same time, these results also implied that the 5XFAD model has similarities but is not entirely consistent with human disease. WNT7B, a ligand of the Wnt signaling pathway, has been studied to demonstrate that dysregulation of the Wnt signaling pathway may be associated with synaptic failure and impaired cognitive function in neurodegenerative diseases [47]. Wnt-7b increases presynaptic protein aggregation and synaptic vesicle recycling [48]. It is suggested that alterations in common Wnt signaling pathways associated with early AD pathology and cognitive decline [49]. TRAF1, TNF receptor associated factor 1, plays a key role in the immune system. It is regarded as a key signal transducers of many receptor families, such as innate immune receptors and adaptive immune receptors [50]. SPRC (S-Propargyl-cysteine) has been shown to attenuate spatial learning and memory deficits via the TNF signaling and NF- $\mathrm{KB}$ signaling pathways in a rat model induced by lipopolysaccharide [51], but further studies are needed to elucidate the relationship between TRAF1 and AD. ROD1, the gene encodes an RNA-binding protein that was initially thought to act as a differentiation inhibitor [52], and later found to be a member of the heterogeneous nuclear ribonucleoprotein family. It also found to be involved in selective splicing of mRNA precursors [53]. Recently, pyrophosphate sequencing analysis has shown that the methylation level of ROD1 is closely associated with aging in centenarians [54]. RAET1E, raet1e (encoding Raet1) is a novel atherosclerotic gene [55]. Both atherosclerosis and AD are thought to be associated with inflammation [56]. But the

A

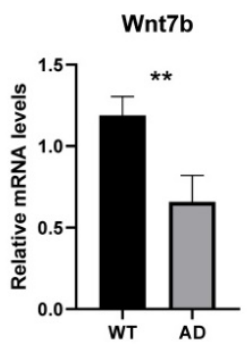

E



B



$\mathrm{F}$

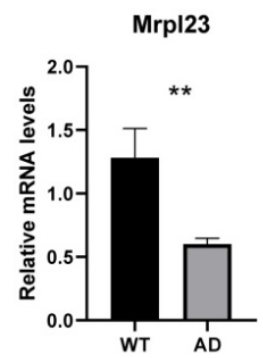

relationship between RAET1E and $\mathrm{AD}$ has not been much studied, which may also be a potential target for AD research. MRPL23, mitochondria ribosomal protein L23, mitochondrial ribosomal protein (MRP) is an important component of the structural and functional integrity of the mitochondrial complex and has a major impact on the translational function of mitochondria [57]. While the accumulation of damaged mitochondria is one of the causes of neurodegeneration in $\mathrm{AD}$, and impaired mitochondrial autophagy has also been observed in the hippocampus of AD patients [58]. But the direct relationship between MPRL23 and AD remains to be determined by further studies. GPR174 (G protein-coupled receptor 174) could induce rapid degranulation of mast cells $[59,60]$, limit proliferation of regulatory T cells [61] and enhance phagocytosis of apoptotic neutrophils by macrophages $[62,63]$. ZNF543 (zinc finger protein 543), this gene has a wide range of physiological functions in a variety of cellular processes, which including apoptosis, cell proliferation and differentiation [64]. OR4K2 (olfactory receptor family 4 subfamily $\mathrm{K}$ member 2 ), olfactory receptor protein is a member of the large family of G protein-coupled receptors (GPCR) produced by a single coding exon gene. Olfactory receptors are responsible for recognition and G protein-mediated odor signaling. EDN3, Endothelin 3 is a powerful vasoconstrictor peptide in the adult enteric nervous system. EDN3 controls differentiation of enteric nervous system progenitors under the regulation of sox10 and ZEB2 [65]. ARMCX5, located on chromosome Xq22.1, a region associated with epilepsy [66], but there was no study in AD.

C

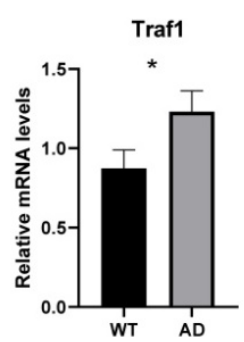

G

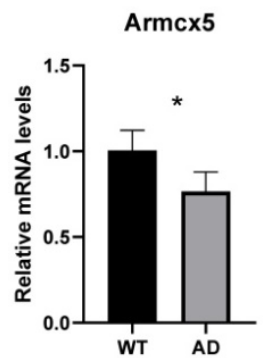

D

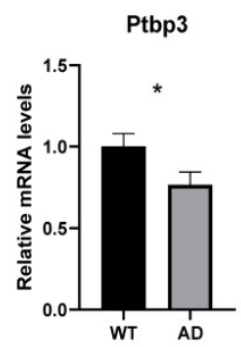

$\mathrm{H}$

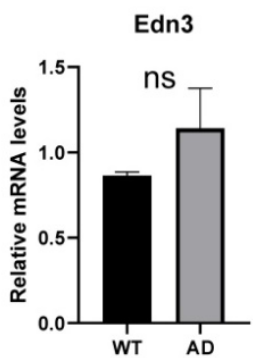

Figure 10. The relative mRNA levels of 8 genes in AD mouse models. (A-H) The relative mRNA levels of Wnt7b, Gprl 74, Trafl, Ptbp3, Raetl e, Mrpl23, Armcx5 and Edn3 in control and 5XFAD samples compared with the control. ns $P>0.05$, *p $<0.05$, **p $<0.01$ and $* * * p<0.001$. 
Of course, our study has some limitations. Firstly, the data we used was from a public database with a limited sample size, so it may not be a good representation of the true pathological state. Then, we did not validate the key genes in vivo and in vitro experiments. In addition, although we found that M1 macrophage is associated with $\mathrm{AD}$, but the origin of M1 macrophage and relationship with $A D$ need further studies to determine.

In conclusion, based on the expression matrix of $\mathrm{AD}$ and control, we initially explored the immune infiltration in the prefrontal cortex of $\mathrm{AD}$ patients and identified M1 macrophages and black module were associated with the occurrence of AD. We performed CIBERSORT and WGCNA to analyze the relationship between $\mathrm{AD}$ and immune cells for the first time. We identified 10 key genes associated with $\mathrm{AD}$, which might be used as new targets for immunotherapy in AD patients.

\section{Abbreviations}

AD: Alzheimer's disease; GEO: gene expression omnibus; WGCNA: weighted gene co-expression network analysis; LASSO: least absolute shrinkage and selection operator; RF: random forest; CNS: central nervous system; Tregs: $\mathrm{T}$ regulatory cells (TRegs); GS: gene significance; MM: module importance; KEGG: kyoto encyclopedia of genes and genomes; ROC: receiver operating characteristic; TC-NER: Transcription-Coupled Nucleotide Excision Repair; AUC: area under the curve; MRP: mitochondrial ribosomal protein; GPCR: G protein-coupled receptors.

\section{Acknowledgements}

We appreciate the support of all lab members and Dr. Jianming Zeng from the University of Macau, and we would like to thank 'GEO database' for providing high quality biological data.

\section{Funding}

This project was supported by grants from the National Key R\&D Program of China (2017YFE0196600), National Natural Science Foundation of China (31830111, 81771333), Key Research and Innovation Program of Shanghai Municipal Education Commission (2019-01-07-00-07E00040).

\section{Author Contributions}

Chenming Liu and $\mathrm{X}_{\mathrm{i}}$ Zhang designed the research topic. Chenming Liu drafted the manuscript, and analyzed the data. Huazhen Chai, Sutong $\mathrm{Xu}$ and Qiulu Liu participated in the revision of the manuscript. Siguang $\mathrm{Li}$ and Yuping Luo were involved in the work instruction and financial support.

\section{Competing Interests}

The authors have declared that no competing interest exists.

\section{References}

1. Qiu C, Kivipelto M, von Strauss E. Epidemiology of Alzheimer's disease: occurrence, determinants, and strategies toward intervention. Dialogues Clin Neurosci. 2009; 11: 111-28.

2. Kalaria RN, Maestre GE, Arizaga R, Friedland RP, Galasko D, Hall K, et al. Alzheimer's disease and vascular dementia in developing countries: prevalence, management, and risk factors. The Lancet Neurology. 2008; 7: 812-26.

3. Hardy J, Selkoe DJ. The Amyloid Hypothesis of Alzheimer's Disease: Progress and Problems on the Road to Therapeutics. Science. 2002; 297: 353.

4. Bloom GS. Amyloid- $\beta$ and Tau: The Trigger and Bullet in Alzheimer Disease Pathogenesis. JAMA Neurology. 2014; 71: 505-8.

5. Braak H, Braak E. Neuropathological stageing of Alzheimer-related changes. Acta neuropathologica. 1991; 82: 239-59.

6. Hansen DV, Hanson JE, Sheng M. Microglia in Alzheimer's disease. J Cell Biol. 2018; 217: 459-72.

7. Novellino F, Saccà V, Donato A, Zaffino $\mathrm{P}$, Spadea MF, Vismara M, et al. Innate Immunity: A Common Denominator between Neurodegenerative and Neuropsychiatric Diseases. Int J Mol Sci. 2020; 21: 1115.

8. Cai Z, Qiao P-F, Wan C-Q, Cai M, Zhou N-K, Li Q. Role of Blood-Brain Barrier in Alzheimer's Disease. Journal of Alzheimer's Disease. 2018; 63: 1223-34.

9. Keren-Shaul H, Spinrad A, Weiner A, Matcovitch-Natan O, Dvir-Szternfeld R, Ulland TK, et al. A Unique Microglia Type Associated with Restricting Development of Alzheimer's Disease. Cell. 2017; 169: 1276-90.e17.

10. Salter MW, Stevens B. Microglia emerge as central players in brain disease. Nature Medicine. 2017; 23: 1018-27.

11. Solé-Domènech S, Cruz DL, Capetillo-Zarate E, Maxfield FR. The endocytic pathway in microglia during health, aging and Alzheimer's disease. Ageing research reviews. 2016; 32: 89-103

12. Bajetto A, Bonavia R, Barbero S, Schettini G. Characterization of chemokines and their receptors in the central nervous system: physiopathological implications. Journal of Neurochemistry. 2002; 82: 1311-29.

13. Owens T, Khorooshi R, Wlodarczyk A, Asgari N. Interferons in the central nervous system: A few instruments play many tunes. Glia. 2014; 62: 339-55.

14. Norden DM, Godbout JP. Review: Microglia of the aged brain: primed to be activated and resistant to regulation. Neuropathology and Applied Neurobiology. 2013; 39: 19-34.

15. Spittau B. Aging Microglia-Phenotypes, Functions and Implications for Age-Related Neurodegenerative Diseases. Frontiers in aging neuroscience. 2017; 9: 194-.

16. Marschallinger J, Iram T, Zardeneta M, Lee SE, Lehallier B, Haney MS, et al. Lipid-droplet-accumulating microglia represent a dysfunctional and proinflammatory state in the aging brain. Nature neuroscience. 2020; 23: 194-208.

17. Habib N, McCabe C, Medina S, Varshavsky M, Kitsberg D, Dvir-Szternfeld R, et al. Disease-associated astrocytes in Alzheimer's disease and aging. Nature neuroscience. 2020; 23: 701-6.

18. Liddelow SA, Barres BA. Reactive Astrocytes: Production, Function, and Therapeutic Potential. Immunity. 2017; 46: 957-67.

19. Liddelow SA, Guttenplan KA, Clarke LE, Bennett FC, Bohlen CJ, Schirmer L, et al. Neurotoxic reactive astrocytes are induced by activated microglia. Nature. 2017; 541: 481-7.

20. Park J-C, Han S-H, Mook-Jung I. Peripheral inflammatory biomarkers in Alzheimer's disease: a brief review. BMB Rep. 2020; 53: 10-9.

21. Dong $Y$, Lagarde $J$, Xicota $L$, Corne $H$, Chantran $Y$, Chaigneau $T$, et al. Neutrophil hyperactivation correlates with Alzheimer's disease progression. Annals of neurology. 2018; 83: 387-405.

22. Picone P, Di Carlo M, Nuzzo D. Obesity and Alzheimer's disease: Molecular bases. European Journal of Neuroscience. 2020; 52: 3944-50.

23. Whitmer RA, Gustafson DR, Barrett-Connor E, Haan MN, Gunderson EP, Yaffe K. Central obesity and increased risk of dementia more than three decades later. Neurology. 2008; 71: 1057.

24. Beydoun MA, Kivimaki M. Midlife obesity, related behavioral factors, and the risk of dementia in later life. Neurology. 2020; 94: 53.

25. Qiu WQ, Folstein MF. Insulin, insulin-degrading enzyme and amyloid- $\beta$ peptide in Alzheimer's disease: review and hypothesis. Neurobiology of Aging. 2006; 27: 190-8.

26. Wyatt-Johnson SK, Brutkiewicz RR. The Complexity of Microglial Interactions With Innate and Adaptive Immune Cells in Alzheimer's Disease. Frontiers in aging neuroscience. 2020; 12: 592359-.

27. Zhang K, Tian L, Liu L, Feng Y, Dong Y-B, Li B, et al. CXCL1 contributes to $\beta$-amyloid-induced transendothelial migration of monocytes in Alzheimer's disease. PLoS One. 2013; 8: e72744-e. 
28. Zenaro E, Pietronigro E, Bianca VD, Piacentino G, Marongiu L, Budui S, et al. Neutrophils promote Alzheimer's disease-like pathology and cognitive decline via LFA-1 integrin. Nature Medicine. 2015; 21: 880-6.

29. Kolaczkowska E, Kubes P. Neutrophil recruitment and function in health and inflammation. Nature Reviews Immunology. 2013; 13: 159-75.

30. Saresella M, Calabrese E, Marventano I, Piancone F, Gatti A, Calvo MG, et al. PD1 Negative and PD1 Positive CD4+ T Regulatory Cells in Mild Cognitive Impairment and Alzheimer's Disease. Journal of Alzheimer's Disease. 2010; 21: 927-38.

31. Dansokho C, Ait Ahmed D, Aid S, Toly-Ndour C, Chaigneau T, Calle V, et al. Regulatory $\mathrm{T}$ cells delay disease progression in Alzheimer-like pathology. Brain. 2016; 139: 1237-51.

32. Ritchie ME, Phipson B, Wu D, Hu Y, Law CW, Shi W, et al. limma powers differential expression analyses for RNA-sequencing and microarray studies. Nucleic acids research. 2015; 43: e47-e.

33. Newman AM, Liu CL, Green MR, Gentles AJ, Feng W, Xu Y, et al. Robust enumeration of cell subsets from tissue expression profiles. Nature methods. 2015; $12: 453-7$.

34. Langfelder P, Horvath S. WGCNA: an R package for weighted correlation network analysis. BMC bioinformatics. 2008; 9: 559-.

35. Yu G, Wang L-G, Han Y, He Q-Y. clusterProfiler: an R package for comparing biological themes among gene clusters. Omics : a journal of integrative biology. 2012; 16: 284-7.

36. $\mathrm{Yu} \mathrm{G}, \mathrm{He} \mathrm{Q}-\mathrm{Y}$. ReactomePA: an R/Bioconductor package for reactome pathway analysis and visualization. Molecular bioSystems. 2016; 12: 477-9.

37. Friedman J, Hastie T, Tibshirani R. Regularization Paths for Generalized Linear Models via Coordinate Descent. Journal of statistical software. 2010; 33: $1-22$.

38. Chen H, Boutros PC. VennDiagram: a package for the generation of highlycustomizable Venn and Euler diagrams in R. BMC bioinformatics. 2011; 12: 35-.

39. Sing $T$, Sander O, Beerenwinkel N, Lengauer T. ROCR: visualizing classifier performance in R. Bioinformatics. 2005; 21: 3940-1.

40. Robin X, Turck N, Hainard A, Tiberti N, Lisacek F, Sanchez J-C, et al. pROC: an open-source package for $\mathrm{R}$ and $\mathrm{S}+$ to analyze and compare ROC curves. BMC bioinformatics. 2011; 12: 77-.

41. Oakley H, Cole SL, Logan S, Maus E, Shao P, Craft J, et al. Intraneuronal beta-amyloid aggregates, neurodegeneration, and neuron loss in transgenic mice with five familial Alzheimer's disease mutations: potential factors in amyloid plaque formation. The Journal of neuroscience : the official journal of the Society for Neuroscience. 2006; 26: 10129-40.

42. Wegiel J, Wisniewski HM. The complex of microglial cells and amyloid star in three-dimensional reconstruction. Acta neuropathologica. 1990; 81: 116-24.

43. Gate D, Rezai-Zadeh K Fau - Jodry D, Jodry D Fau - Rentsendorj A, Rentsendorj A Fau - Town T, Town T. Macrophages in Alzheimer's disease: the blood-borne identity. Journal of Neural Transmission. 2010; 117: 961-70.

44. Mildner A, Schlevogt B, Kierdorf K, Böttcher C, Erny D, Kummer MP, et al. Distinct and non-redundant roles of microglia and myeloid subsets in mouse models of Alzheimer's disease. The Journal of neuroscience : the official journal of the Society for Neuroscience. 2011; 31: 11159-71.

45. Minhas PS, Liu L, Moon PK, Joshi AU, Dove C, Mhatre S, et al. Macrophage de novo $\mathrm{NAD}(+)$ synthesis specifies immune function in aging and inflammation. Nature immunology. 2019; 20: 50-63.

46. Garcia-Alloza M, Borrelli LA, Rozkalne A, Hyman BT, Bacskai BJ. Curcumin labels amyloid pathology in vivo, disrupts existing plaques, and partially restores distorted neurites in an Alzheimer mouse model. Journal of Neurochemistry. 2007; 102: 1095-104.

47. De Ferrari GV, Inestrosa NC. Wnt signaling function in Alzheimer's disease. Brain Res Brain Res Rev. 2000; 33: 1-12.

48. Inestrosa NC, Varela-Nallar L. Wnt signaling in the nervous system and in Alzheimer's disease. Journal of Molecular Cell Biology. 2014; 6: 64-74.

49. Riise J, Plath N, Pakkenberg B, Parachikova A. Aberrant Wnt signaling pathway in medial temporal lobe structures of Alzheimer's disease. Journal of Neural Transmission. 2015; 122: 1303-18.

50. Xie P. TRAF molecules in cell signaling and in human diseases. Journal of molecular signaling. 2013; 8: 7-

51. Gong Q-H, Wang Q, Pan L-L, Liu X-H, Xin H, Zhu Y-Z. S-Propargyl-cysteine, a novel hydrogen sulfide-modulated agent, attenuates lipopolysaccharideinduced spatial learning and memory impairment: Involvement of TNF signaling and NF-KB pathway in rats. Brain, Behavior, and Immunity. 2011; 25: $110-9$.

52. Yamamoto $H$, Tsukahara $K$, Kanaoka $Y$, Jinno $S$, Okayama $H$. Isolation of a mammalian homologue of a fission yeast differentiation regulator. Molecular and cellular biology. 1999; 19: 3829-41.

53. Spellman R, Llorian M, Smith CWJ. Crossregulation and functional redundancy between the splicing regulator PTB and its paralogs $\mathrm{NPTB}$ and ROD1. Molecular cell. 2007; 27: 420-34.

54. Zeng Q, Chen X, Ning C, Zhu Q, Yao Y, Zhao Y, et al. Methylation of the genes ROD1, NLRC5, and HKR1 is associated with aging in Hainan centenarians. BMC medical genomics. 2018; 11: 7-

55. Rodríguez JM, Wolfrum S, Robblee M, Chen KY, Gilbert ZN, Choi J-H, et al. Altered expression of Raet1e, a major histocompatibility complex class 1-like molecule, underlies the atherosclerosis modifier locus Ath11 10b. Circulation research. 2013; 113: 1054-64.
56. Wingo AP, Fan W, Duong DM, Gerasimov ES, Dammer EB, Liu Y, et al. Shared proteomic effects of cerebral atherosclerosis and Alzheimer's disease on the human brain. Nature neuroscience. 2020; 23: 696-700.

57. Cheong A, Lingutla R, Mager J. Expression analysis of mammalian mitochondrial ribosomal protein genes. Gene Expression Patterns. 2020; 38: 119147.

58. Fang EF, Hou Y, Palikaras K, Adriaanse BA, Kerr JS, Yang B, et al. Mitophagy inhibits amyloid- $\beta$ and tau pathology and reverses cognitive deficits in models of Alzheimer's disease. Nature neuroscience. 2019; 22: 401-12.

59. Iwashita M, Makide K, Nonomura T, Misumi Y, Otani Y, Ishida M, et al. Synthesis and Evaluation of Lysophosphatidylserine Analogues as Inducers of Mast Cell Degranulation. Potent Activities of Lysophosphatidylthreonine and Its 2-Deoxy Derivative. Journal of Medicinal Chemistry. 2009; 52: 5837-63.

60. Martin TW, Lagunoff D. Interactions of lysophospholipids and mast cells. Nature. 1979; 279: 250-2.

61. Bellini F, Bruni A. Role of a serum phospholipase A1 in the phosphatidylserine-induced T cell inhibition. FEBS Letters. 1993; 316: 1-4.

62. Frasch SC, Berry KZ, Fernandez-Boyanapalli R, Jin H-S, Leslie C, Henson PM, et al. NADPH oxidase-dependent generation of lysophosphatidylserine enhances clearance of activated and dying neutrophils via G2A. The Journal of biological chemistry. 2008; 283: 33736-49.

63. Frasch SC, Fernandez-Boyanapalli RF, Berry KZ, Leslie CC, Bonventre JV, Murphy RC, et al. Signaling via macrophage G2A enhances efferocytosis of dying neutrophils by augmentation of Rac activity. The Journal of biological chemistry. 2011; 286: 12108-22.

64. Lupo A, Cesaro E, Montano G, Zurlo D, Izzo P, Costanzo P. KRAB-Zinc Finger Proteins: A Repressor Family Displaying Multiple Biological Functions. Current genomics. 2013; 14: 268-78.

65. Watanabe Y, Stanchina L, Lecerf L, Gacem N, Conidi A, Baral V, et al. Differentiation of Mouse Enteric Nervous System Progenitor Cells Is Controlled by Endothelin 3 and Requires Regulation of Ednrb by SOX10 and ZEB2. Gastroenterology 2017; 152: 1139-50.

66. Zhou J, Goldberg EM, Leu NA, Zhou L, Coulter DA, Wang PJ. Respiratory failure, cleft palate and epilepsy in the mouse model of human Xq22.1 deletion syndrome. Human molecular genetics. 2014; 23: 3823-9. 